\title{
Enforced Face-to-Face Stacking of Organic Semiconductor Building Blocks within Hydrogen-Bonded Molecular Co-Crystals
}

Anatoliy N. Sokolov, Tomislav Friščić, Leonard R. MacGillivray*

Department of Chemistry

University of Iowa, Iowa City, IA

52245 (USA)

\section{SUPPLEMENTARY MATERIAL}

S1. General Information.

S2. Synthesis of 2,5-bis(4-pyridylethynyl)thiophene (1).

S3. Synthesis of 9,10-bis(4-pyridylethynyl)anthracene (2).

S4. Synthesis of 2(1) $\cdot 2(5$-methylresorcinol) (3).

S5. Synthesis of 2(2) $\cdot 2(5$-iodoresorcinol) (4).

S6. References

* University of Iowa, Iowa City, IA, USA, 52242, TELEPHONE: (319) 335-3504, FAX: (319) 335-1270

Email: len-macgillivray@uiowa.edu 
S1. General Information.

All chemicals were purchased from Aldrich Co., unless otherwise noted. 9,10diiodoanthracene $^{1}$ and 5 -iodoresorcinol ${ }^{2}$ were prepared according to literature procedures. All crystal data were measured on a Nonius Kappa CCD single-crystal X-ray diffractometer at liquid nitrogen temperature.

S2. 2,5-bis(4-pyridylethynyl)thiophene (1).

A round-bottom flask was charged with 2,5-diiodothiophene (0.672 g, 2 mmol), 4ethynylpyridine $(0.430 \mathrm{~g}, 4.2 \mathrm{mmol}), \mathrm{PdCl}_{2}\left(\mathrm{PPh}_{3}\right)_{2}(70 \mathrm{mg}, 5 \mathrm{~mol} \%)$, and $0.5 \mathrm{ml}$ piperidine in $25 \mathrm{ml} \mathrm{THF}$. The solution was allowed to stir for $10 \mathrm{~min}$ at room temperature and $\mathrm{CuI}$ (19 $\mathrm{mg}, 5$ mol \%) was subsequently added. The mixture was kept under reflux conditions for a period of 8 hours. The solution was concentrated using a rotary evaporator. The product was purified by column chromatography using neutral alumina and a 95:5 mixture of diethyl ether:MeOH as the eluent. Subsequent recrystallizations from hexanes afforded $200 \mathrm{mg}(\approx 35 \%)$ of $1 .{ }^{1} \mathrm{H}$ NMR data for 1 (DMSO-d $\left.{ }_{6}, 300 \mathrm{MHz}\right): \delta$ 7.54-7.57 (6H's, m, pyridine, thiophene), $\delta$ 8.64-8.66 (4H's, d, pyridine). Crystal data for 1: monoclinic, space group $P 22_{1} / \mathrm{c}, a=10.1694(10) \AA, b=$ 13.4373(13) $\AA, c=10.6937(11) \AA, \beta=98.135(5)^{\circ}, V=1446.58(11) \AA^{3}, Z=4, \rho_{\text {calc }}=1.31$ $\mathrm{g} / \mathrm{cm}^{3}$ and $R_{1}=0.0374$ for 2580 reflections with $I>2 \sigma(I)$.

S3. 9,10-bis(4-pyridylethynyl)anthracene (2).

A round-bottom flask was charged with 9,10-diiodoanthracene (0.86 g, 2 mmol), 4ethynylpyridine $(0.5 \mathrm{~g}, 4.85 \mathrm{mmol}), \mathrm{PdCl}_{2}\left(\mathrm{PPh}_{3}\right)_{2}(70 \mathrm{mg}, 5 \mathrm{~mol} \%)$, in $33 \mathrm{ml}$ diethylamine solution. The solution was allowed to stir for $10 \mathrm{~min}$ at room temperature and $\mathrm{CuI}(19 \mathrm{mg}, 5 \mathrm{~mol}$ 
\%) was subsequently added. The mixture was kept under reflux conditions for a period of 8 hours. The solution was concentrated using a rotary evaporator. The product was purified by column chromatography using neutral alumina and a 97.5:2.5 mixture of diethyl ether:MeOH as the eluent. Subsequent recrystallizations from toluene afforded $220 \mathrm{mg}(\approx 29 \%)$ of $\mathbf{2}$. ${ }^{1} \mathrm{H}$ NMR data for 2 (DMSO-d $6,300 \mathrm{Mhz}): \delta 7.82-7.90$ (8H's, m, pyridine, anthracene), $\delta 8.70-8.77$ ( $8 \mathrm{H}$ 's, $\mathrm{m}$, pyridine, anthracene). Crystal data for 2: monoclinic, space group $C$ 2/c, $a=11.0531(11) \AA$, $b=23.9650(20) \AA, c=7.2633(7) \AA, \beta=97.055(5)^{\circ}, V=1909.39(12) \AA^{3}, Z=4, \rho_{\text {calc }}=1.32$ $\mathrm{g} / \mathrm{cm}^{3}$ and $R_{1}=0.0541$ for 1781 reflections with $I>2 \sigma(I)$.

S4. 2(1) 2(5-methylresorcinol) (3)

A closed vial containing $5 \mathrm{mg}$ of $\mathbf{1}, 4.2 \mathrm{mg}$ of 5-methylresorcinol, and $1 \mathrm{ml}$ of $\mathrm{CH}_{3} \mathrm{CN}$ was heated to reflux and allowed to cool slowly. Subsequent evaporation provides single crystals suitable for X-ray diffraction analysis. ${ }^{1} \mathrm{H}$ NMR data for 3 (DMSO-d $\left.{ }_{6}, 300 \mathrm{Mhz}\right): \delta 2.10-2.11$ (3H's, s, methyl), $\delta$ 5.98-6.01 (3H's, br. s, resorcinol), $\delta$ 7.54-7.57 (6H's, m, pyridine, thiophene), $\delta$ 8.64-8.68 (4H's, dd, pyridine), $\delta 8.99$ (2H's, s, resorcinol-OH). Crystal data for 3 : triclinic, space group $P \overline{1}, a=8.1439(8) \AA, b=19.0985(19) \AA, c=28.074(30) \AA, \alpha=$ $89.826(5)^{\circ}, \beta=88.740(5)^{\circ}, \gamma=89.570(5)^{\circ}, V=4365.33(9) \AA^{3}, Z=2, \rho_{\text {calc }}=1.25 \mathrm{~g} / \mathrm{cm}^{3}, R_{1}=$ 0.0719 for 7486 reflections with $I>2 \sigma(I)$.

S5. 2(2) 2(5-iodoresorcinol) (4).

A closed vial containing $3 \mathrm{mg}$ of $1,1.9 \mathrm{mg}$ of 5-iodoresorcinol, and $1 \mathrm{ml}$ of a 5:1 mixture of $\mathrm{CHCl}_{3}: \mathrm{MeOH}$ was heated to reflux and allowed to cool slowly. Subsequent evaporation provides single crystals suitable for X-ray diffraction analysis. ${ }^{1} \mathrm{H}$ NMR data for 4 (DMSO- $\mathrm{d}_{6}$, 
300Mhz): $\delta 6.17-6.19(1 \mathrm{H}, \mathrm{m}$, resorcinol), $\delta 6.55-6.56(2 \mathrm{H}$ 's, d, resorcinol), $\delta$ 7.84-7.90 (8H's, $\mathrm{m}$, pyridine, anthracene), $\delta 8.71-8.77$ (8H's, m, pyridine, anthracene), $\delta 9.56$ (2H's, br. s, resorcinol- $O H)$. Crystal data for 4: triclinic, space group $P \overline{1}, a=7.6588(8) \AA, b=10.0715(10)$ $\AA, c=17.6024(18) \AA, \alpha=81.751(5)^{\circ}, \beta=82.555(5)^{\circ}, \gamma=84.830(5)^{\circ}, V=1328.85(13) \AA^{3}, Z=$ $2, \rho_{\text {calc }}=1.54 \mathrm{~g} / \mathrm{cm}^{3}$ and $R_{1}=0.0480$ for 3594 reflections with $I>2 \sigma(I)$.

\section{S6. References}

1) Bachmann, W. E.; Kloetzel, M. C. J. Org. Chem. 1988, 53, 2120-2122.

2) Dol, G. C.; Kamer, P. C. J.; van Leeuwen, W. N. M. Eur. J. Org. Chem. 1998, 359-364. 